\title{
Quem é quem na saúde ambiental brasileira? I dentificação e caracterização de grupos de pesquisas e organizações da sociedade civil
}

\author{
Who is who in Brazilian environmental health? \\ Identification and characterization of academic groups \\ and civil society organizations
}

Carlos M achado deFreitas ${ }^{1}$

Ana M aria Testa Tambellini ${ }^{2}$

Gabriel Eduardo Schultz ${ }^{1}$

ValériaAndradeBertolini ${ }^{1}$

Francisco de Abreu Franco N etto ${ }^{1}$

${ }^{1}$ Centro de Estudos da Saúdedo Trabalhador e Ecologia Humana, Escola Nacional deSaúdePública, Fiocruz. Rua Leopoldo Bulhões 1480/302, M anguinhos. 21041-210 Rio deJaneiro RJ. carlosmf@ensp.fiocruz.br 2 Instituto de Estudos em Saúde Coletiva, UniversidadeFederal do Rio deJaneiro.
Abstract In this paper we present the results of the first phase of the project Who is Who in Brazilian Environmental $\mathrm{Health}$. The aim of this project is to identify and characterize the Academic Groups and Civil Society Organizations acting on the field of environmental health that are able to contribute both to the strengthening of its technical and scientific basis, and to the dialogue with organized civil society. The identification took place through the data source available at CNPq (Research Groups Directory), ABON G (Brazilian Association of N on-Governmental Organizations), FBOM S (Brazilian Forum of NGOs and Social Movements for Environment and Sustainable Development) and RBJA (Brazilian N etwork for Environmental Justice). The results were presented and discussed based on time evolution, geographic distribution and areas of research and action. Final considerations point to the great potential for dialogue between experts and non experts, governmental and non-governmental, in order to createthefoundation for a extended peer community capable of combining policies, knowledge, technologies and actions, seeking the comprehension and search of solutions to the establishment of health as a prerequisite and $X$ a result of well being and full life. Key words Environmental health, Academic groups, Civil society organizations, Health and environment
Resumo Neste artigo, apresentamos os resultados da primeira fasedo projeto " $Q$ uem équem na saúde ambiental brasileira". 0 objetivo desteprojeto é identificar e caracterizar grupos de pesquisas e organizações da sociedade civil atuantes no campo da saúde ambiental, em condições de contribuir tanto ao fortalecimento de suas bases técnicas e ci entíficas quanto a facilitar o diálogo com a sociedadecivil organizada. A identificação ocorreu através informações di sponíveis no CN Pq (diretório dos grupos de pesquisas), na Associação Brasileira de O rganizações $N$ ão Governamentais ( $A B O N G$ ), no Fórum Brasileiro de ON Gs e M ovimentos Sociais para o M eio Ambiente e o De senvolvimento Sustentável (FBOMS) e na Rede Brasileira de Justiça Ambiental (RBJA). Os re sultados foram apresentados e discutidos tendo como basea evolução temporal, a distri buição geográfica e as áreas de pesquisa e de atuação. As considerações finais apontam para o grande potencial dediálogo entreespecialistasenão especialistas, governamentais enão governamentais, para criar as bases de uma comunidade ampliada de pares capaz de combinar políticas, conhecimentos, tecnologias e ações para a compreensão e busca de soluções para a constituição de uma saúde como pré requisito e como resultado do bem estar e da vida plena.

Palavras-chave Saúdeambiental, Grupos depesquisa, Organizações da sociedade civil, Saúde e meio ambiente 
Introdução

A saúde ambiental éárea de grande importância ecomplexidadeno campo de conhecimento epráticas de intervenção da saúde pública e coletiva, bem como de relação direta com as questões re lacionadas ao desenvolvimento sustentável ${ }^{1,2}$. Vem cada vez mais ganhando proeminência nas instituições governamentais e não governamentais, acadêmicas e não acadêmicas.

Deacordo com o documento "Subsídios para a Construção da Política Nacional de SaúdeAmbiental" ${ }^{3}$, a [...] saúde ambiental compreende a área da saúde pública, afeita aos conhecimentos científicos eà formulação de políticas públicas e às correspondentes intervenções [ações] relacionadas à interação entre a saúde humana e os fatores do meio ambiente [...]. Esta definição permite compreender a saúde ambiental como uma área do campo da saúde pública ecoletiva, quese apropria e produz conhecimentos a partir de múltiplas disciplinas, dentro e fora da grande área das ciências da saúde, bem como um âmbito de práticas que envolve não só ações de instituições do setor saúde, mas também de outros setores de governo, as instituições acadêmicas e as organizações da sociedade civil (OSC).

Um dos objetivos do projeto "Quem é quem na saúde ambiental brasileira" é fortalecer a área da saúde ambiental através da identificação e caracterização de atores sociais em condições de contribuir tanto ao fortalecimento de suas bases técnicas e científicas quanto ao diálogo com a sociedade civil organizada, criando as condições para uma comunidade ampliada de pares ${ }^{4}$. Para atingir este objetivo, o projeto desenvolveu uma pesquisa dos grupos de pesquisas (GP) certificados pelo CN Pq e das organizações da sociedade civil (OSC) organizadas em redes e fóruns que venham tratando de temas e problemas relacionados à saúde ambiental.

Este projeto vem sendo realizado na Escola N acional deSaúde Pública Sérgio Arouca daFundação Oswaldo Cruz (ENSP/Fiocruz) a partir de uma iniciativa e financiamento da Coordenação de Vigilância em Saúde Ambiental da Secretária de Vigilância em Saúde (CGVAM /SVS), ambas do Ministério da Saúde (MS), e conta com o apoio do Grupo de Trabalho Saúde e Ambiente da Associação Brasileira de Pós-Graduação em Saúde Coletiva (ABRASCO).

0 projeto visa subsidiar a 1 a Conferência Nacional de Saúde Ambiental, a ser realizada no final do ano 2009, com a intenção de traçar as diretrizes de uma política nacional de saúde am- biental capaz de integrar o conjunto de ações do governo com a pesquisa científica eda sociedade civil organizada. Numa área de grande complexidadeepistemológica eontológica como éa saúdeambiental, ao mesmo tempo inserida na agenda política e social, este tipo de integração não ocorre de modo automático e sem conflitos. Embora grande parte da sociedade coincida no diagnóstico de problemas que emergem na interseção do meio ambiente com a saúde humana, o consenso costuma não se ampliar às medidas que devem ser tomadas para resolvê-los, em especial, na atual conjuntura internacional decrise econômica, ambiental e social.

Os temas e problemas da área da saúde ambiental envolvem uma ampla multiplicidade de cenários e interações, em diversas escal as espaciais e temporais, sendo por isto a presença de incertezas e ignorâncias sobre os sistemas socioambientais inerentes às suas questões. Simultaneamente, envolvem conflitos de interesses e perspectivas sobre os mesmos nos temas e problemas relacionados aos processos de produção/ consumo e mudanças ambientais/condições de saúde. Estas características inerentes aos temas e problemas desta área exigem que se constitua uma comunidade ampliada de pares para uma melhor compreensão e busca de soluções (especialistas enão-especialistas, governamentaisenão governamentais) ${ }^{4-7}$.

A identificação dos grupos cujas pesquisas guardam al guma relação com os temas da saúde ambiental éimportanteem dois aspectos. Primeiro, porque permite identificar e caracterizar os atores sociais que constituem a base da produção científica, daformação acadêmica edo desenvolvimento técnico etecnológico no país. Esteéo primeiro passo para um processo de envolvimento de pesquisadores que, organizados em GPs, etendo járeconhecidaà necessidadedemultidisciplinaridade/multiprofissionalidade da área, possam contribuir para o fortalecimento das bases científicas e técnicas de uma política pública de saúde ambiental. Este passo deve tornar visível eampliar as possibilidades de articulações disciplinares e geográficas entreos GPseinstituições acadêmicas envolvidas, assim como áreas afins ${ }^{7}$. Segundo, porqueo envolvimento destes atores sociais poderácontribuir para o estabelecimento deuma agenda de áreas temáticas essenciais para estudos e pesquisas relacionados aos processos que envolvem a articulação entre saúde, ambiente e desenvolvimento sustentável. Como observado no documento do M inistério da Saúde e do Conselho Nacional de Saúde', para que esta agenda seja 
construída, é necessário que seja produzida de formaarticuladacom entidades no campo da ciência etecnologia, entre outras, e buscando incentivar e estimular através dos agentes financiadores o engajamento dos pesquisadores e cientistas.

Por sua vez, a identificação das OSC é igualmente importante para que a área possa fortalecer o diálogo produtivo, solidário e democrático. Este diálogo deve ser a base para uma parceria que resulte em um processo de participação efetiva da sociedade no controle social e tomada de decisões das políticas públicas afetas à saúde ambiental. Por outro lado, deve oferecer possibilidades concretas aos cidadãos de ter acesso ao conhecimento sobre a relação do ambiente com a saúde e sua situação no país, como também sobre as atividades e programas nesta área, realizadas pelo setor saúde em todos os seus níveis. Trata-se com isto de também criar condições e instrumentos para poder auscultar as necessidades e a satisfação com os serviços, bem como os anseios e percepções das comunidades e indivíduos sobre sua saúde e condicionantes. Esta ausculta permitiria maior contextualização dos problemas de saúde em relação à sua diversidade local eregional em termos epidemiológicos, econômicos e culturais, levando em conta as necessidades específicas de grupos vulneráveis ${ }^{3,7}$.

Com base nestas concepções, o projeto "Quem é quem na saúde ambiental brasileira", foi estruturado como um instrumento que possa contribuir para a consolidação e governança da saúde ambiental no Brasil. N este artigo, apresentamos os resultados da primeira fase do projeto, isto é, a informação levantada no processo deidentificação ecaracterização de atores sociais em instituições acadêmicas e organizações da sociedade civil brasileira. Os próximos passos envolvem tanto a construção de um banco de dados amigável de acesso público que permita identificar por temas, estadose regiões, bem como uma maior interação com os mesmos na busca de informações mais específicas e detal hadas de suas pesqui sas, ações eatuações em temas relacionados à interseção do meio ambiente e a saúde, através das conferências estaduais e/ou regionais de saúde ambiental.

\section{Materiais emétodos}

Foram construídas duas bases de dados: uma agrupando as informações sobre os grupos de pesquisa e outra em relação às organizações da sociedadecivil.
O projeto Diretório de Grupos de Pesquisa teveinício em 1992, com o objetivo deestruturar uma base de dados - disponível para consulta pública - contendo informações sobre os grupos de pesquisa em atividade no país, localizados em universidades, instituições isoladas de ensino superior, institutos de pesquisa científica, institutos tecnológicos e laboratórios de pesquisa e desenvolvimento de empresas estatais ou ex-estatais. Os levantamentos não incluem os grupos localizados nas empresas do setor produtivo.

Para coletar informações que permitam identificar e caracterizar os grupos acadêmicos que desenvolvem pesquisa na interface saúde e meio ambiente, foi realizada uma busca sistemática na base corrente do diretório de grupos de pesquisa do CN Pq (http://dgp.cnpq.br/buscaoperacional) com diferentes palavras-chave e utilização dos filtros de busca (UF - Instituição - Grande área - Área de pesquisa). As pesquisas foram realizadas utilizando as expressões "saúde e ambiente e ambiental" e "saúde e sustentabilidade e sustentável". Esta busca foi iniciada em outubro de 2008 e concluída em novembro do mesmo ano e permitiu estruturar um banco de dados contendo as seguintes informações:

. Nome / ano de formação / instituição

- Líder(es) / endereço completo / endereço eletrônico e página web

. Área temática de atuação (grande área, área e linhas de pesquisa)

- Relação com as linhas programáticas da CGVAM

As informações em relação às OSC, por sua vez, foram coletadas a partir de três diferentes fontes de dados, correspondentes aos cadastros da Associação Brasileira de Organizações Não Governamentais ( $A B O N G$ ), do Fórum Brasileiro de ONGs e M ovimentos Sociais para o M eio Ambiente e o Desenvolvimento Sustentável (FBOMS) e da Rede Brasileira de Justiça Ambiental (RBJA).

A ABONG foi fundada em 1991, tendo como objetivos e ações prioritárias promover o intercâmbio, a articulação, a divulgação de informações e a reflexão entre as 0 N Gs, orientada para a ampliação da cidadania, a constituição e expansão de direitos, a justiça social e a consolidação de uma democracia participativa.

A FBOM S foi fundada em 1990 , tendo como objetivo facilitar a participação da sociedade civil no processo da Rio-92. Na atualidade, constituise como espaço de articulação de O NGs e movimentos sociais (sindicatos, populações tradicionais e indígenas, associações comunitárias, entre 
outros), tendo como missão unificar, através de grupos de trabal ho, as questões socioeconômicas e ambientais na busca de um desenvolvimento sustentável, com a finalidade de atingir uma sociedade mais justa, equitativa e ambientalmente correta.

A RBJA foi fundada em 2001, tendo como objetivo combater a injustiça ambiental no Brasil (situações em que a carga dos danos ambientais do desenvolvimento se concentra de modo predominante, em locais onde vivem populações pobres). Constitui uma articulação de representantes de movimentos sociais, ON Gs, sindicatos e pesquisadores/as de todo o Brasil para promover ações de denúncias, elaborar estratégias de ação entre os múltiplos atores de lutas ambientais e realizar um trabalho de pesquisa, divulgação e pressão política no sentido de inserir na agenda pública uma perspectiva de preservação ambiental que comece a ser pensada também em termos de distribuição e justiça.

Para as organizações da sociedade civil, estruturou-se um banco de dados a partir da busca de informações nos sítios eletrônicos da ABONG (http://www.abong.org.br), da FBOM S (http://www.fboms.org.br/) e da RBJA (http:// www.justicaambiental.org.br). Esta busca foi iniciada em outubro de 2008 e concluída em junho de2009.

Neste caso, o critério foi identificar aquelas organizações que, de fato, desenvolvem atividades na interface da saúde eo meio ambiente (participação em grupos de trabalho, implementação de projetos, dentre outras). Em função da ausência parcial de dados nas fontes consultadas, informações suplementares foram coletadas, quando disponível, nas páginas de Internet das próprias organizações de sociedade civil em questão. Estruturou-se um banco de dados a partir do seguinte formulário:

- Dados gerais (nome / sigla / ano de formação / responsável / personalidade jurídica)

. Endereço completo / endereço eletrônico e página web

- Área geográfica e/ou bioma de atuação

. População-alvo

. Atuação em grupos de trabalho ou envolvimento na implementação de projetos

. M issão e/ou objetivo CGVAM

- Relação com as linhas programáticas da

. Fonte de dados

Para o levantamento na ABO NG, a busca foi realizada no banco de projetos identificando as ONGs com projetos realizados nos últimos cin- co anose combinando os termos "saúde" e"meio ambiente" com "agricultura", "trabalho e renda", "desenvolvimento da economia regional", "questões urbanas", "questões agrárias". Na ABONG, as OSCs foram levantadas a partir do cadastro existente e de acesso público, permitindo facilmenteidentificar e caracterizar por projetos, tendo sido concluído em fevereiro de 2009. Para o levantamento na FBO MS, a busca foi realizada a partir da identificação das OSCs atuantes nos quinze grupos de trabal ho existentes até fevereiro de 2009. Identificadas as OSCs, buscaram-se informações disponíveis na Internet para cada uma das mesmas. Para o levantamento na RBJA, foram incluídas na busca de informações todas as 75 OSC s que são membros da mesma, já que todas as ações e campanhas são decididas consensualmente por todos os seus membros, tendo sido concluído em abril de 2009.

Neste artigo, para os 489 GPs e 196 OSCs identificados, nos detivemos na análise da evolução temporal e distribuição espacial. A caracterização da forma de inserção dos GPs e OSC s centraram-se nos seus aspectos coletivos. Para os GPs, foi realizada considerando sua inserção nas oito grandes áreas do conhecimento e 76 áreas do conhecimento do CN Pq. Para a caracterização das OSCs, foram consideradas as suas áreas e formas de atuação na forma de associações, redes efóruns, uma vez queseus modos deinserções são bastante diversificadas.

\section{Resultadosediscussão}

\section{Evolução temporal}

A Figura 1 mostra a evolução temporal do surgimento de novos GPs e OSCs. As colunas representam o percentual denovas entidades criadas nas últimas décadas.

Para as OSCs, constatamos que o surgimento de novas teve as melhores condições nos últimos anos da década de oitenta e durante toda a década denoventa. N esses anos, houveuma sinergia de fatores históricos de natureza política diferente, que contribuiu à emergência denovas $\mathrm{OSCS}$ de perfil ambientalista em todo o mundo, mas que repercutiu de forma singular no Brasil dos anos da redemocratização, do debate constituintee da agenda de ampliação da cidadania, devendo mencionar-se neste processo alguns marcos, como a realização da VIII Conferência Nacional de Saúde em 1986 e a Constituição de 1988; a divulgação do relatório “N osso futuro comum” pela 


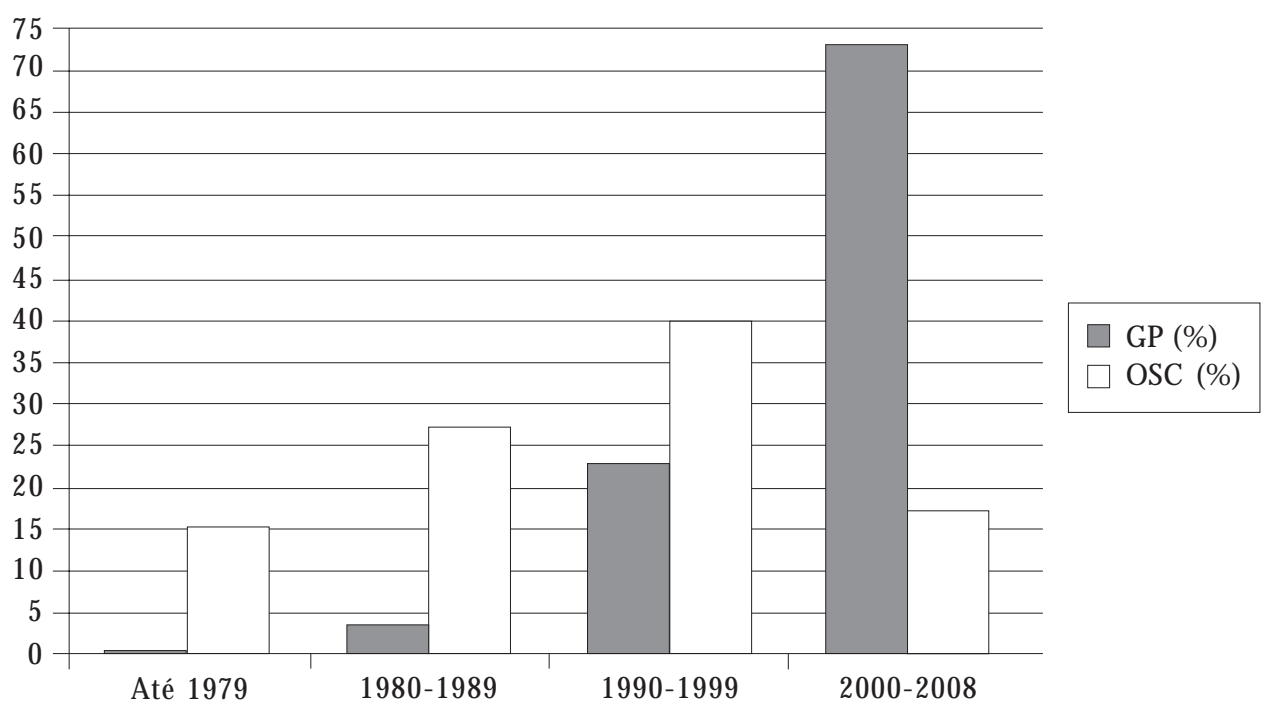

Figura 1. Porcentagem de novos grupos de pesquisas e organizações da sociedade civil componentes do universo da pesquisa por década - 1980-2008.

Fontes: CN Pq, ABONG, FBOM S, RBJA.

O bservação: Os dados dos GPs foram coletados entre 6/10/2008 e 28/11/2008 e os dados das OSC s foram coletados entre $6 / 10 / 2008$ e 26/06/2009.

Comissão Mundial sobre o M eio Ambiente eDesenvolvimento (CM M AD) em 1987 ea realização da Conferência das Nações Unidas sobre Meio Ambientee Desenvolvimento, realizada em 1992, na cidade do Rio de Janeiro, Brasil, tendo como um de seus resultados a Agenda 21 , um programa de ações para o século XXI que constitui um marco na questão ambiental. É exatamenteneste contexto que surgem a ABONG (1991) e a FBOM S (1990), sendo emblemático queo encontro de fundação tenha ocorrido em sala da Faculdade de Saúde Pública da USP. Mas também é preciso observar que, ao longo dos anos noventa, houve uma tendência detransferência do gerenciamento de parte da questão social que era deresponsabilidade do Estado para o chamado "terceiro setor", estimulando e financiando atividades de um importante setor da sociedade civil.

Para os GPs, é possível observar que seu número tem um crescimento exponencial na passagem do século XX para o XXI, o que pode ser explicado, em boa medida, como um dos resultados concretos das políticas de consolidação da pesquisa científica aplicadas no Brasil nas últimas décadas. N este processo, assistimos à el evação do financiamento, da formação de mestres e doutores e de ampliação dos programas de pósgraduação e dos trabalhos publicados em periódicos científicos. N este contexto, $73 \%$ dos grupos de pesquisa que compõem o universo deste levantamento foram criados a partir do ano 2000 , ou seja, quando a questão ambiental já seencontrava consolidada e as questões relacionadas à saúde ambiental iniciavam a se institucionalizar no setor saúde com a estruturação da vigilância em saúde ambiental (Decreto no 3.450, de 9 de maio de 2000) e ganhavam cada vez mais proeminência nos meios de comunicação.

\section{Distribuição geográfica}

Conforme podemos verificar na Tabela 1, os 489 GPs estiveram distribuídos em todas as unidades da federação (UF). Deste total ,38\% concentraram-se na Região Sudeste, vindo em seguida as Regiões Sul (24\%) e N ordeste (23\%) com cerca de $1 / 4$ cada uma. Nas Regiões N orte (9\%) e Centro-Oeste (6\%), encontrou-se menor percentual de GPs. Dentro das UFs, chama a aten ção o grande número de GPs nos estados do Rio de Janeiro (76) eSão Paulo (73), em contraste com a situação de outras UFs que tiveram me- 
nos de $1 \%$ dos GPs, concentrados principalmentena Região Nordeste, como Alagoas, M aranhão, Piauí e Sergipe, além de M ato Grosso do Sul na Região Centro-O este.

Para que setenha um elemento comparativo, podemos considerar que a distribuição geográfica dos GPs identificados nesta pesquisa representa uma distribuição mais heterogênea do Censo dos Grupos de Pesquisas em 2006. Naquele ano, 50,4\% concentravam-se na Região Sudeste e com as Regiões $\mathrm{N}$ ordeste eN orte apresentando percentuais menores, sendo $15,5 \%$ e $4,4 \%$ respectivamente.
Em relação as OSCs, das 196 identificadas, $45 \%$ concentram-sena Região Sudeste, vindo em seguida as Regiões Nordeste (18\%). As regiões Sul (14\%), N orte (12\%) eCentro-O este eN orte (11\%) estiveram bem próximas em termos percentuais. Dentro das UFs, chama a atenção os casos de UFs sem nenhuma OSC identificada, como Alagoas e Sergipe na Região Nordeste e Amapá e Roraima na Região N orte. Dos dados sobre as OSCS, ainda queencontremosuma concentração na Região Sudeste, temos, por outro lado, uma distribuição bastante próxima para as outras regiões.

Tabela 1. Distribuição dos grupos de pesquisa e organizações da sociedade civil por estado e regiões.

\begin{tabular}{|c|c|c|c|c|c|c|}
\hline Região / Estado & $\begin{array}{l}\mathrm{N}^{\circ} \\
\text { GPS }\end{array}$ & $\begin{array}{l}\text { \% dos GPs nas } \\
\text { UFs em relação } \\
\text { às regiões }\end{array}$ & $\begin{array}{c}\text { \% dos GPs } \\
\text { nas regiões } \\
\text { do país }\end{array}$ & $\begin{array}{c}\mathrm{N}^{\circ} \\
\mathrm{OSCS}\end{array}$ & $\begin{array}{l}\text { \% das OSCs nas } \\
\text { UFs em relação } \\
\text { às regiões }\end{array}$ & $\begin{array}{c}\text { \% das OSCs } \\
\text { nas regiões } \\
\text { do país }\end{array}$ \\
\hline Centro-Oeste & 31 & 100 & 6 & 22 & 100 & 11 \\
\hline Distrito Federal & 8 & 26 & & 13 & 59 & \\
\hline Goiás & 5 & 16 & & 2 & 09 & \\
\hline M ato Grosso & 16 & 52 & & 3 & 14 & \\
\hline M ato Grosso do Sul & 2 & 06 & & 4 & 18 & \\
\hline Nordeste & 114 & 100 & 23 & 36 & 100 & 18 \\
\hline Alagoas & 4 & 04 & & - & - & \\
\hline Bahia & 43 & 37 & & 12 & 33 & \\
\hline Ceará & 17 & 15 & & 9 & 25 & \\
\hline M aranhão & 4 & 04 & & 5 & 14 & \\
\hline Paraíba & 8 & 07 & & 1 & 01 & \\
\hline Pernambuco & 21 & 18 & & 3 & 09 & \\
\hline Piauí & 4 & 04 & & 3 & 09 & \\
\hline Rio Grande do Norte & 8 & 07 & & 3 & 09 & \\
\hline Sergipe & 5 & 04 & & - & - & \\
\hline Norte & 42 & 100 & 9 & 23 & 100 & 12 \\
\hline Acre & 3 & 07 & & 3 & 13 & \\
\hline Amapá & 2 & 05 & & - & - & \\
\hline Amazonas & 15 & 36 & & 4 & 17 & \\
\hline Pará & 13 & 31 & & 10 & 44 & \\
\hline Rondônia & 4 & 09 & & 4 & 17 & \\
\hline Roraima & 2 & 05 & & - & - & \\
\hline Tocantins & 3 & 07 & & 2 & 09 & \\
\hline Sudeste & 184 & 100 & 38 & 87 & 100 & 45 \\
\hline Espírito Santo & 6 & 03 & & 1 & 01 & \\
\hline M inas Gerais & 29 & 16 & & 9 & 10 & \\
\hline Rio de Janeiro & 76 & 41 & & 40 & 46 & \\
\hline São Paulo & 73 & 40 & & 37 & 43 & \\
\hline Sul & 118 & 100 & 24 & 28 & 100 & 14 \\
\hline Paraná & 27 & 23 & & 10 & 36 & \\
\hline Rio Grande do Sul & 47 & 40 & & 11 & 39 & \\
\hline Santa Catarina & 44 & 37 & & 7 & 25 & \\
\hline Total & 489 & & 100 & 196 & & 100 \\
\hline
\end{tabular}

Fontes: CN Pq, ABON G, FBO M S, RBJA.O bservação: Os dados dos GPs foram coletados entre6/10/2008 e28/11/2008 e os dados das OSC foram coletados entre 6/10/2008 e 26/06/2009. 
Analisando comparativamente os GPs e OSCs, constatamos que, para estas últimas, a concentração é bem maior na Região Sudeste e distribuída a partir daí de modo bastante próximo nas outras regiões. Analisando a distribuição de GPs dentro de cadauma das regiões, constatamos que al gumas U Fs concentram os maiores percentuais, constituindo-se em eventuais centros dereferências de GPsnas instituições acadêmicas, como $M$ ato Grosso na Região CentroOeste $(52 \%)$, Bahia na Região N ordeste $(37 \%$, sendo mais do que o dobro de Pernambuco, com $18 \%$ ), Amazonas e Pará na Região N orte (36\% e $31 \%$, respectivamente), Rio de J aneiro eSão Paulo na Região Sudeste ( $41 \%$ e 40\%) e Rio Grande do Sul e Santa Catarina na Região Sul ( $40 \%$ e $37 \%$, respectivamente). Q uando analisamos as OSC S, os eventuais centros se deslocam para outras U Fs, como Goiás na Região Centro Oeste (59\%), Bahia e Ceará na Região N ordeste (33\% e $25 \%$, respectivamente), Pará na Região Norte ( $44 \%$, sendo mais do duas vezes e meia os percentuais de Amazonas e Rondônia), Rio de Janeiro eSão Paulo na Região Sudeste (46\% e 43\%, respectivamente) e Rio Grande do Sul e Paraná na Região Sul (39\% e 36\%, respectivamente).

0 perfil desta distribuição não parece estar determinado por uma única variável, mas como um resultado do processo de desenvolvimento econômico nacional, que conjuga de forma diacrônica dimensões históricas, geográficas, demográficas e sociopolíticas, que resultam em uma concentração dos GPs e OSCs em determinadas regiões e UFs dentro das mesmas, o que reflete dinâmicas regionais e locais distintas.

Áreas de pesquisa e de atuação

Deacordo com o Censo do Diretório de Grupos de Pesquisa 2006, disponível até a conclusão desta pesquisa, existiam 21.024 grupos cadastrados no CN Pq. A identificação daquel es queguardam al guma relação com a área da saúde ambiental foi efetuada por meio das palavras-chave "saúde e ambiente" (353 resultados); "saúde ambiental" (304 resultados); "saúde e sustentável" ( 63 resultados) e "saúde e sustentabilidade" (53 resultados). 0 resultado total das buscas foi de 764 grupos, aos quais se somaram nove grupos de pesquisa que compõem simultaneamente o cadastro do CN Pq e de temas da RBJA. N este universo de 773 resultados, foi preciso identificar quais grupos apareciam em mais de uma busca e subtrair todas as redundâncias. Isto reduziu 0 número de grupos a 489, ou seja, cerca de 2,3\% do total dos GPs do censo de 2006. Cabe destacar que este procedimento de levantamento padronizado identifica de modo automático os GPs queincluíram alguma das palavras-chave debusca no momento dese cadastrarem; porém, a saúde pode estar se referindo a um tipo de "saúde" diferente da humana (animal, vegetal, ecossistêmica), bem como "ambiente" pode se referir a um entorno não diretamente relacionado a área da saúde ambiental (por exemplo, ambiente familiar ou ambiente escolar).

Observou-se que, proporcionalmente, as palavras-chave incluindo os termos "ambiente/ambiental" localizaram mais grupos cadastrados nas grandes áreas "ciências da saúde". Já as que incluíam os termos "sustentável/sustentabilidade" Iocalizaram mais grupos das "ciências humanas" e das "ciências sociais aplicadas". Por um lado, foi possível conferir que há um total de 1.606 grupos localizáveis com a palavra-chave "saúde" dentro da grande área "ciências da saúde", dos quais só $141(9 \%)$ incluem a palavra "ambiente" e 10 $(0,6 \%)$ incluem a palavra "sustentável". Estes dados revelam dois aspectos importantes e conectados, se tomamos como referência a Agenda 21. Em primeiro lugar, revela que as questões ambientais ocupam um espaço considerável nas "ciências da saúde", indo ao encontro ao enunciado no capítulo 6 da Agenda 21, denominado "A saúde ambiental como prioridade social para a promoção da saúde". De qualquer modo, devemos chamar a atenção que, de modo inverso e mais orientado para os efeitos sobre os humanos, temos 870 GPs (54\%) que incluem a palavra "doença". Em segundo lugar, revela que nas"ciências da saúde" ainda é periférico o reconhecimento de palavras, como "sustentável" e "sustentabilidade", que expressam a busca de meios para implementar 0 desenvolvimento sustentável, tal como expresso no Capítulo 35, "Ciência para o desenvolvimento sustentável".

Situação similar encontramos para a palavra "ecossistemas". A mesma vem ocupando a agenda científica global desde o início do século XXI como um aspecto diretamenterelacionado à saúde e ao bem-estar humano, sendo isto expresso tanto em publicações de OSC s, como o relatório 2000/2001 do World Resources Institute People and ecosystems: the fraying web of life ${ }^{8}$, como em um dos relatórios específicos do Millennium Ecosystem Assessment, Ecosystems and human well-being: health synthesis ${ }^{9}$. Porém, o percentual de GPs que a reconhecem no seu trabalho nas "ciências da saúde" éainda mais periférico. Apenas $7(0,4 \%)$ grupos cadastrados nas "ciências 
da saúde" incluem a palavra "ecossistemas". De modo inverso, dentre os grupos de pesquisa cadastrados para a área "ecologia", pertencente à grande área "ciências biológicas", há 108 grupos localizáveis pela palavra-chave "ecossistemas", dos quais somente quatro incluem o termo "saúde humana". Parece ser ainda forte a tendência das "ciências da saúde" tratar os ecossistemas de modo bastante reduzido e fortemente influenciado pelo modelo ecológico (agente/hospedeiro/ ambiente), ao mesmo tempo em que há, nas "ciências biológicas", particularmente na "ecologia", a tendência de tratar os ecossistemas dissociados dos aspectos relacionados a saúde humana.

O Diretório de Grupos de Pesquisa do CN Pq está organizado em oito grandes áreas de pesquisa, cada uma delas composta por áreas de pesquisa mais específicas, sendo ao todo 76 áreas de pesquisa. Todas as oito grandes áreas têm ao menos um grupo de pesquisa levantado nesta pesquisa; porém, a com maior número de grupos cadastrados é "ciências da saúde", e nela destaca-se a área "saúde coletiva", com 120 (cerca de $25 \%$ ) dos 489 grupos, sendo a única que agrupa mais de uma centena. A segundagrandeárea mais importante é "ciências humanas", com 88 grupos, na qual duas das suas dez áreas (educação e psicologia) concentram o $60 \%$ do total (53 grupos). Também se destaca a área "engenharia sanitária", que representa quase $50 \%$ dos grupos levantados na grandeárea "engenharias". Em síntese, das 76 áreas de pesquisa, só quatro agrupam mais de vinte grupos e onze áreas agrupam dez ou mais grupos (Tabela 2).

Tabela 2. Identificação das áreas de pesquisa e grandes áreas que apresentaram dez ou mais grupos de pesquisa.

\begin{tabular}{llc}
\hline \multicolumn{1}{c}{ Áreas de pesquisas } & \multicolumn{1}{c}{ Grandes áreas } & $\begin{array}{c}\text { № de } \\
\text { grupos }\end{array}$ \\
\hline Saúde coletiva & Ciências da saúde & 120 \\
Educação & Ciências humanas & 31 \\
Engenharia sanitária & Engenharias & 25 \\
Psicologia & Ciências humanas & 22 \\
Medicina & Ciências da saúde & 17 \\
Ecologia & Ciências biológicas & 16 \\
Direito & Ciências sociais aplicadas & 15 \\
Sociologia & Ciências humanas & 15 \\
Geociências & Ciências exatas e da Terra & 14 \\
Enfermagem & Ciências da saúde & 12 \\
Farmácia & Ciências da saúde & 12 \\
Engenharia civil & Engenharias & 11 \\
Planejamento urbano e regional & Ciências sociais aplicadas & 11 \\
Economia & Ciências sociais aplicadas & 10 \\
Química & Ciências exatas e da Terra & 10 \\
\end{tabular}

D os 489 grupos que compõem o universo da pesquisa, 278 são liderados por mulheres ou, no caso deter mais de um líder, uma mulher aparece como líder principal.

$\mathrm{N}$ a sua grande maioria, as instituições certificadoras dos GPs são universidades federais (44\%); seguidas das universidades estaduais, regionais e munici pais (30\%); dos centros e institutos de pesquisa ( $15 \%$ ) euniversidades particulares. 0 perfil institucional não éhomogêneo em todo o território nacional. Em estados da Região Sul, bem como no Estado de São Paulo, há uma maior proporção relativa de universidades estaduais, regionais emunicipais, bem como universidades particulares (em especial as de cunho religioso). Por sua vez, no Estado do Rio de Janeiro, há uma maior proporção de grupos certificados por centros e institutos de pesquisa em relação ao resto do Brasil, em especial devido ao grande número de grupos certificados neste estado pela Fundação O swaldo Cruz.

Uma busca no Scielo Saúde Pública (www.scielosp.org) nos permite identificar poucos trabalhos que tratem da relação entre a pesquisa e produção científica na área da saúde ambiental. Dos três encontrados, só um cita os GPs, restringindo-se aos da área da saúde coletiva ${ }^{10}$, e os outros dois tratam principalmente das publicações científicas relacionadas à mesma nos âmbitos nacional ${ }^{11}$ e internacional ${ }^{12}$. N este artigo, ao ampliarmos a busca para todas as grandes áreas eáreas dos grupos de pesquisa do CN Pq, vislumbramos não somente o potencial da área da saúde coletiva para a saúde ambiental, mas também seus limites ao tratar de temas importantes como a sustentabilidadeambiental ou o desenvolvimento sustentável. Também vislumbramos o potencial que outras áreas apresentam para a construção de conhecimentos científicos que podem ser apropriados pela saúde ambiental e a possibilidade de constituição de redes de pesquisa multi e interdisciplinares envolvendo GPs de diversas outras grandes áreas, como as "ciências humanas" e "ciências sociais aplicadas" para as questões ligadas ao desenvolvimento sustentável e a "ecologia" nas "ciências biológicas" para as questões relacionadas aos ecossistemas, e ambas para a constituições de abordagens integradas.

Para a caracterização das OSCs, consideramos as suas formas de atuação em associações, redes e fóruns, bem como suas áreas de atuação.

A ABONG é composta por 269 ONGs, sendo que 24 (cerca de 9\%) atendiam aos critérios de estar trabalhando ou ter trabalhado com projetos envolvendo temas que guardem alguma rela- 
ção com a saúde ambiental, como as questões agrárias e urbanas, desenvolvimento econômico regional e trabal ho e renda, que estão incluídas dentre as suas áreas deatuação (ver Tabela 3). De acordo com as informações disponíveis na I nternet, suas principais formas de articulação e mobilização ocorrem de três modos principais. 0 primeiro é através de campanhas em favor de temas como da água (para São Paulo), contra o trabal ho escravo e infantil, contra a desigualdade ea pobreza, mudança de hábitos deconsumo em favor do clima, entre tantos outros. 0 segundo é através de manifestos assinados por diversas organizações, como, por exemplo, em defesa de minorias étnicas, culturais e outros grupos vulneráveis (como crianças eadolescentes), contra o programa nuclear brasileiro, pela não liberação de produtos transgênicos e de apoio à ANVISA na normatização dos mesmos. 0 terceiro é o In-
ter-Redes, que articula redes e fóruns de OSCs que atuam de diversas formas e em diversos temas, o que inclui tanto a FBOM S como a RBJA, assim muitos outros tratando de temas relacionados aos direitos de minorias e grupos vulneráveis, a questão da segurança alimentar, da reforma urbana e do lixo, para citar alguns exemplos.

No levantamento do FBOMS, das 581 OSCs cadastradas, foram identificadas 136 OSCs $(23,4 \%)$ atuantes nos quinze grupos de trabal ho (GT) que definem suas princi pais áreas de atuação (ver Tabela 3). Os GTs são a instância de produção temática equal itativa do FBOM S. Além dos GTs, o FBO M S participa em redes de articulação nacionais e internacionais, campanhas e eventos. $N$ as redes de articulação nacionais, entre outras, se encontram a RBJA, a Rede Jubileu Sul, o Fórum Nacional de Participação Popular. No caso das redes internacionais, participa, por

Tabela 3. Formas de organização temática das organizações da sociedade civil na ABONG, FBOM S e RBJA.

\begin{tabular}{|c|c|c|}
\hline $\begin{array}{c}\text { ABONG - Áreas temáticas de } \\
\text { atuação }\end{array}$ & FBOMS - Grupos de trabalho & $\begin{array}{l}\text { RBJA - Grupos de trabalho } \\
\text { e banco temático }\end{array}$ \\
\hline 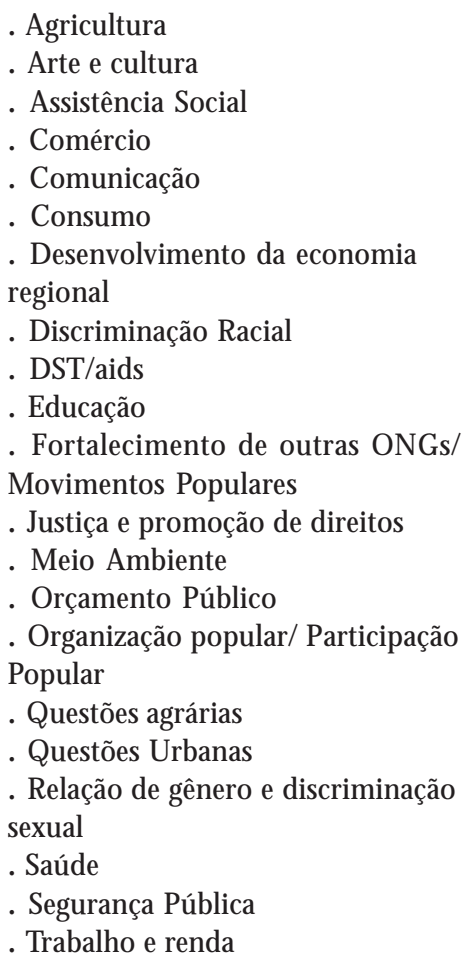 & $\begin{array}{l}\text {. Agenda } 21 \\
\text {. Água } \\
\text {. Clima } \\
\text {. Colegiados Socioambientais } \\
\text {. Comércio e M eio Ambiente } \\
\text {. Direito Ambiental } \\
\text {. Formação Política } \\
\text {. Energia } \\
\text {. Florestas } \\
\text { - Integração } \\
\text {. Juventude } \\
\text { - Novas Tecnologias } \\
\text { - Químicos } \\
\text { - Sociobiodiversidade } \\
\text {. Turismo Sustentável }\end{array}$ & $\begin{array}{l}\text { Grupos de trabalho } \\
\text {. GT de combate ao Racismo } \\
\text { Ambiental } \\
\text {. GT de Químicos } \\
\text { Banco temático } \\
\text {. Atividades geradoras de } \\
\text { injustiça ambiental } \\
\text {. Eixos de luta } \\
\text {. Populações envolvidas e } \\
\text { atingidas } \\
\text {. Experiências, ações e } \\
\text { mobilizações propositivas de } \\
\text { entidades e grupos em torno de } \\
\text { conflitos socioambientais }\end{array}$ \\
\hline
\end{tabular}

Fonte: ABONG, FBOMS, RBJA.

Observação: Os dados das OSC foram coletados entre 6/10/2008 e26/06/2009. 
exemplo, na Rede de Ação pelo Clima-CAN, no Fórum Social Mundial, na Rededeação pelaáguaFAN eno ComitêD iretor da SociedadeCivil Global/PNUM A. Também participa de campanhas como a que luta contra os transgênicos e a importação dos pneus da Organização Mundial do Comércio (OMC). Seus membros também atuam em colegiados e conferências de eventos nacionais einternacionais.

$\mathrm{Na}$ RBJA, foram consideradas todas as 75 OSC s participantes. Suas ações se desenvolvem através da atuação em seus dois GTs - Q uímicos e de Combate ao Racismo Ambiental - e participando de articulações, campanhas e alianças nacionais einternacionais. Os GTsfuncionam como fóruns de divulgação de informações sobre situações de risco e processos políticos de resistência. As articulações nacionais são a de Siderurgia e Relatoria do M eio Ambiente. Entre as alianças na América Latina se encontram Acción Ecológica, GAIA (Alianza Global Anti-Incineración/ Alianza Global para Alternativas a la Incineración), OLCA (Observatorio Latinoamericano de Conflictos Ambientales), Probioma (Productividad, Biosfera, M edio Ambiente) entre outras. Dentreas campanhas desenvolvidas, encontramse o Conflito Fundiário entre indígenas e Aracruz no Espírito Santo, o repúdio à importação de pneus, 0 apoio às Mulheres da Via Campesina, entre outras campanhas. A rede conta também com um banco temático que organiza linhas de ação e documentos (ver Tabela 3).

Em relação ao universo das OSC S, constatamos uma grande diversidade de formas de atuação e organização, predominando dois tipos das quais as ciências sociais têm se ocupado de modo preferencial nas últimas décadas: os movimentos sociais e as ON Gs, coincidindo com os principais atores sociais do nosso universo de estudo. Por movimento social, entende-se um tipo de ação coletiva - contínua e organizada - que se concentra em algum aspecto da mudança social. A maior parte do trabalho teórico recente neste sentido teveinício com a agitação política e social da década de sessenta e início da de setenta ${ }^{13}$. A expressão organização não governamental nasceu na década de sessenta, a partir da iniciativa da Organização das Nações Unidas (ONU) de convidar al gumas organizações civis a presenciar suas assembléias; dado que se trata de uma organização de estados, se buscou diferenciar os níveis de participação de uns e outros ${ }^{14}$. 0 campo das ON Gs é altamente heterogêneo se analisado a partir dos binômios teoria/práxis e fins/ meios, ou seja, diferenciam-se tanto na sua cos- movisão quanto na estratégia metodológica adotada para alcançar seus objetivos, mesmo entre as que, em principio, compartem uma mesma ideologia. O sresultados desteestudo confirmam que ambas as formas de organizações constituem um universo bastante heterogêneo em termos de temas e áreas de atuação, articulados de diversos modos em redes. Ainda que não tratem explicitamente das questões da Saúde Ambiental, abordam os principais temas relacionados aos determinantes sociais e ambientais da saúde.

\section{Considerações finais}

Em nosso entender, a construção da área da saúde ambiental como no campo da saúde públicae coletiva requer uma gama variada de domínio sobre diversas áreas de conhecimentos específicos e articuladas que produzam entendimentos particulares de acordo com a natureza e tipo dos processos em mira, seus desdobramentos e tendências, tendo em vista o objeto saúde. 0 mesmo vale para as tecnologias que deverão concretizar em objetos e relações instrumentais, as possibilidades de uso do conhecimento a serviço das políticas de saúde. Nestesentido, as políticas públicas se constituem no outro elemento desta construção, desde que são formulações da organização coletiva dos desejos de bem-estar e vida plena assumidos pelo Estado a partir de propostas governamentais em sociedades democráticas?

Estes pilares - políticas (desejos e necessidades), conhecimento (compreensão científica da realidade e da vivência das necessidades), tecnologia (construção de instrumentos) e ações (intervenções programáticas) - só podem se viabilizar num serviço específico, no plano da saúde, pela existência de agentes de trabalho/trabalhadores (profissionais de saúde, pesquisadores e técnicos) que ativem os processos dinâmicos de produção envolvidos na concretização das ações da saúde. Por outro lado, as políticas só refletirão os desejos/vontades de cidadania se for fundada uma partici pação e ausculta das coletividades humanas.

Além disso, o conhecimento necessita de informação/dados a serem elaborados pelas investigações científicas na produção de elementos, cuja expressão possa dar conta e tornar visível/ compreensível, para diferentes agentes nas dimensões da qualidade e de quantidades, os problemas concretos vividos pela população em suas relações com ambientes determinados. Desta maneira, seria possível identificar os espaços das 
relações coletivas humanas/ambientes especificados que necessitam de intervenção e, ao mesmo tempo, os estudos aplicados forneceriam as categorias básicas que permitem a construção de tecnologias (relacionais/instrumentais) a ser apropriadas para as intervenções pretendidas pelos serviços ${ }^{7}$.

Como apontado na introdução deste artigo, um dos objetivos do projeto "Quem é quem na saúde ambiental brasileira" éfortalecer a área da saúde ambiental através da identificação e caracterização de dois dos grupos de atores vitais na dinâmica de uma área tão complexa como a que trata da relação saúde e ambiente: os GPs e as OSCs. Estes dois grupos de atores, que envolvem especialistas e não-especialistas, governamentais e não governamentais, integram, com os atores governamentais responsáveis pela execução das políticas públicas, a base de uma comunidade ampliada de pares capaz de combinar políticas, conhecimentos, tecnologias eações para a compreensão e busca de soluções integradas e contextual izadas para a constituição de uma saúde como pré requisito ecomo resultado do bemestar e da vida plena em um mundo mais justo, saudável e sustentável ${ }^{15}$.

\section{Colaboradores}

CM de Freitas e AMT Tambellini participaram da concepção do projeto, do delineamento do universo de coleta de dados, da interpretação e análise dos mesmos. GE Schultz participou do delineamento do universo e da coleta de dados, bem como da interpretação e análise dos mesmos. VA Bertolini e FA Franco Netto participaram da coleta de dados, da interpretação e análise dos mesmos.

\section{Referências}

1. Tambellini AT, Câmara VM . A temática saúde e ambiente no processo de desenvolvimento do campo da saúde coletiva: aspectos históricos, conceituais e metodológicos. Cien Saude Colet 1998; 3(2):47-59.

2. Ribeiro H. Saúde Pública e meio ambiente: evolução do conhecimento e da prática, alguns aspectos éticos. Saúde e Sociedade 2004; 13(1):70-80.

3. Brasil. M inistério da Saúde. Conselho Nacional de Saúde. Subsídios para construção da Política Nacional de Saúde Ambiental. Brasília: M inistério da Saúde; 2007.

4. Funtowicz S, Ravetz J. Ciência pós-normal e comunidades ampliadas de pares face aos desafios ambientais. Hist. cienc. saude-M anguinhos 1997; 4(2):219-230.

5. Funtowicz S, De M archi B. Ciencia posnormal, complejidad reflexiva y sustentabilidad. In: Leff $E$, editor. La complejidad ambiental. M exico: Siglo XXI; 2000. p. 54-84.

6. M unda G. Conceptualising and responding to complexity. Environmental Valuation in Europe (Policy Research Brief). Cambridge: Cambridge Research for the Environment; 2000.

7. Tambellini AT. Documento técnico preliminar descrevendo ações técnicas e políticas que busquem aprimorar a articulação entre as instituições da sociedade civil que tenham ações em saúde ambiental; contendo justificativa, objetivos (geral e específicos), metodologia utilizada e os resultados a serem alcançados. Brasília: Organização Pan-Americana de Saúde; M inistério da Saúde/Secretaria de Vigilância em Saúde/Coordenação Geral de Vigilância em Saúde Ambiental; 2008.

8. World Resources Institute. World Resources 20002001 - People and ecosystems: the fraying web of life. Washington, D.C.: World Resources Institute; 2000. 
9. M illennium Ecosystem Assessment. Ecosystems and human being - Health synthesis. Washington, D.C.: Island Press; 2005.

10. Freitas CM. Problemas ambientais, Saúde Coletiva e Ciências Sociais. Cien Saude Colet 2003; 8(1):137150.

11. Freitas CM. A produção científica sobre o ambiente na Saúde Coletiva. Cad Saude Publica 2005; 21(3):679-701.

12. Camponogara S, Kirchhof ALC, Ramos FRS. Uma revisão sistemática sobre a produção científica com ênfase na relação entre saúde e meio ambiente. Cien Saude Colet 2008; 13(2):427-439.

13. M unk GL. Formação de atores, coordenação social e estratégia política: problemas conceituais do estudo dos movimentos sociais. Dados1997; 40(1):105-126.

14. De Piero S. Organizaciones de la sociedad civil: Tensiones de una agenda en construcción. 1a ed. Buenos Aires: Paidós; 2005.

15. Porto M FS. U ma ecologia política dos riscos - Princípios para integrarmos o local e o global na promoção da saúde e da justiça ambiental. Rio de Janeiro: Fiocruz; 2007.

Artigo apresentado em 10/06/2009

Aprovado em 14/08/2009

Versão final apresentada em 25/08/2009 